\title{
Deviation from the anti-Markovnikov rule: a computational study of the regio- and stereoselectivity of diene hydroboration reactions
}

\author{
Laurence Hamdan $^{1} \cdot$ Khaled Abdel-Maksoud $^{1} \cdot$ Riya Radia $^{1} \cdot$ Janine Boodram $^{1}$ \\ Kwan Y. Man ${ }^{1}$ - Iain McGregor ${ }^{1}$ - Catherine Munteanu ${ }^{1}$ Kishan Muthu ${ }^{1}$. \\ Jannat Poddar $^{1} \cdot$ Joanna Roberts $^{1} \cdot$ Stephanie Sadler $^{1} \cdot$ Nabeela Siddiqi $^{1}$ \\ Sianne Tam ${ }^{1} \cdot$ Anna Andreou $^{2} \cdot$ Oren A. Scherman ${ }^{2} \cdot$ Edina Rosta $^{1}$
}

Received: 17 August 2015 / Accepted: 20 November 2015 / Published online: 26 December 2015

(C) The Author(s) 2015. This article is published with open access at Springerlink.com

\begin{abstract}
Hydroboration and subsequent use of boron compounds in novel organic synthesis have been flourishing in recent years largely due to its amiability in producing asymmetric stereo- and regioselective products. Direct products of diene hydroboration, however, have received little attention, with most substrates being assumed to produce the anti-Markovnikov product expected from textbook organic chemistry understanding. Previous experimental studies have observed the presence of a plethora of hydroboration products, and a significant progress has been made in assigning species to experimental data-though often with contradicting results. This study has used a computational approach employing quantum chemical calculations to determine atomic charges of cyclic and acyclic dienes and correlate these with calculated activation energy barriers in order to predict the regio- and stereoselective outcome of hydroboration reactions. Results indicated a strong correlation between the most polarized atomic charges of double-bonded carbons and the lowest energy transition states as expected. Intriguingly, we identified 1,3-cyclohexadiene as the main example that does
\end{abstract}

Published as part of the special collection of articles "Festschrift in honour of P. R. Surjan".

Electronic supplementary material The online version of this article (doi:10.1007/s00214-015-1768-6) contains supplementary material, which is available to authorized users.

Edina Rosta

edina.rosta@kcl.ac.uk

1 Department of Chemistry, King's College London, London SE1 1DB, UK

2 Melville Laboratory for Polymer Synthesis, Department of Chemistry, University of Cambridge, Lensfield Road, Cambridge CB2 1EW, UK not follow the anti-Markovnikov rule. We proceed to show that in addition to the polarity of the double bonds within a molecule, in this case, the conjugation with the allyl double bond and the specific geometric features of the cyclohexane ring were key stabilizing factors for the unexpected transition state preference, resulting in a regioselectivity that is in quantitative agreement with previous experimental data. Our results further indicated that Re-face attacks and steric factors due to substituents of the substrate influenced mainly the stereoselective outcome of the reaction, also affecting the pathways available to proceed through to complete the hydroboration process.

Keywords Hydroboration - Anti-Markovnikov rule · Markovnikov rule $\cdot$ 11B NMR $\cdot$ Lewis acid-base · Frustrated Lewis pair

\section{Introduction}

Hydroboration is one of the most central reactions pertaining to boron chemistry, due to its involvement in a wide array of chemical synthesis applications [1-5]. Hydroboration of alkenes has great importance because of the wide variety of uses of the resulting organoboranes, such as in Suzuki cross-coupling reactions and aldol condensation reactions [6-8]. Compared with other intermediate compounds, organoboranes are readily prepared from alkenes and alkynes with various structures, giving them their great applicability in organic synthesis [6, 9-11]. Furthermore, the highly stereo- and regioselective nature of hydroboration products has lent themselves to applications in pharmaceuticals [12], as well in the reduction of environmental $\mathrm{CO}_{2}$ [13] and in the polymerization of propylene into polypropylene [14]. Despite the relevance of the direct 

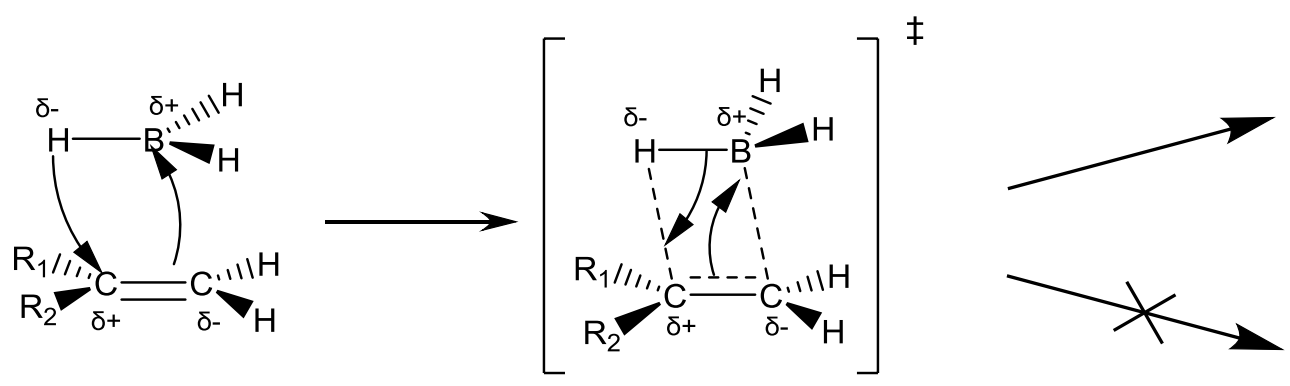<smiles>[R2]C([R2])C[2H]</smiles>

Anti-Markovnikov Product<smiles>[R2]C([R2])([B])[C@@H]([CH])OCOC</smiles>

Scheme 1 General mechanism of hydroboration with the favored anti-Markovnikov product

hydroboration products in the final product specificity, previous studies have mainly focused on the subsequent reactions, such as their oxidation to form alcohols, and the direct unoxidized hydroboration products have until now received little attention [15-17].

Stereo- and regiospecificity of the final synthetic products depends on the specificity of the first hydroboration reaction steps. It is well established that hydroboration favors the anti-Markovnikov regiochemistry and cis stereochemistry (syn-addition, Scheme 1), hence highly useful in chemical synthesis where only one stereoisomer is desired. In hydrocarbons with complex substituents, and more than one double bond, the anti-Markovnikov rule is not directly applicable (i.e., the number of hydrogens at two non-equivalent carbon atoms of the same double bond can be equal), and determining the reaction specificity is not immediately obvious. Simplified explanations of hydroboration use the positions of resulting hydroxyl groups to assign the positions of boron attachment and infer the reaction mechanism. This, however, is known to be inaccurate, as an oxidized product can arise from several different organoboranes [17], and a mechanistic explanation is missing that describes the complete process, including the specific identity of the unoxidized compounds [17]. In addition, owing to the high reactivity and sensitivity of the direct hydroboration products to oxidation, their study using solely analytical techniques is highly challenging. Here we studied potential direct hydroboration reaction products focusing on possible pathways depicted in Scheme 2.

We characterized the specificity of the direct hydroboration reaction products of straight chain and cyclic dienes using computational methods. It was previously thought that only partial hydroboration takes place in dienes, resulting in unsaturated reaction products described by Brown and Bhat [18]. Our recent study [17] demonstrated that hydroboration was not limited to one of the double bonds, and that in fact polymers formed as a result of fully saturated, boron-containing hydrocarbons cross-linking together. We report here the results of quantum chemical calculations of hydroboration reactions, focusing on the regiospecificity of the obtained products. We compare reaction energy barriers and partial charges of carbon atoms to predict the most prevalent products. We validate our structural models by comparing calculated and experimental ${ }^{11} \mathrm{~B}$ NMR chemical shifts.

\section{Results and discussion}

We focused primarily around the ten cyclic, and one noncyclic dienes (Fig. 1), with experimental data available from previous work for eight [17]. Hydroboration of the initial substrates yields a monosubstituted species, which can further react to form various fully hydroborated products, depending on the ratio of the borane and the reactant diene [17]. The amount of diene available to react affects the ratios of the resulting products, and its excess might only allow the first step of the reaction to proceed and thus yield a monosubstituted olefin. This is well documented in the example of hydroboration of 1,3-cyclohexadiene [18, 19], when hydroboration proceeds only to the first step in Scheme 2, and both allyl (2-cyclohexene-1-ol) and homoallyl (3-cyclohexene-1-ol) species are formed, with the first one in excess (Fig. 2). Interestingly, up to $90 \%$ regioselectivity was observed for the allyl product with specific hydroboration agents [18]. This unexpected regioselective outcome [19] posed an interesting case in our analysis and is discussed further in Sect. 2.1.

\subsection{Monohydroboration products of dienes}

In our first analysis step, we were interested in determining the regio- and stereoselectivity of the hydroboration reactions under reaction conditions where monohydroboration products are formed primarily. To analyze the selectivity of the reactions, we focused on the rate-determining step 


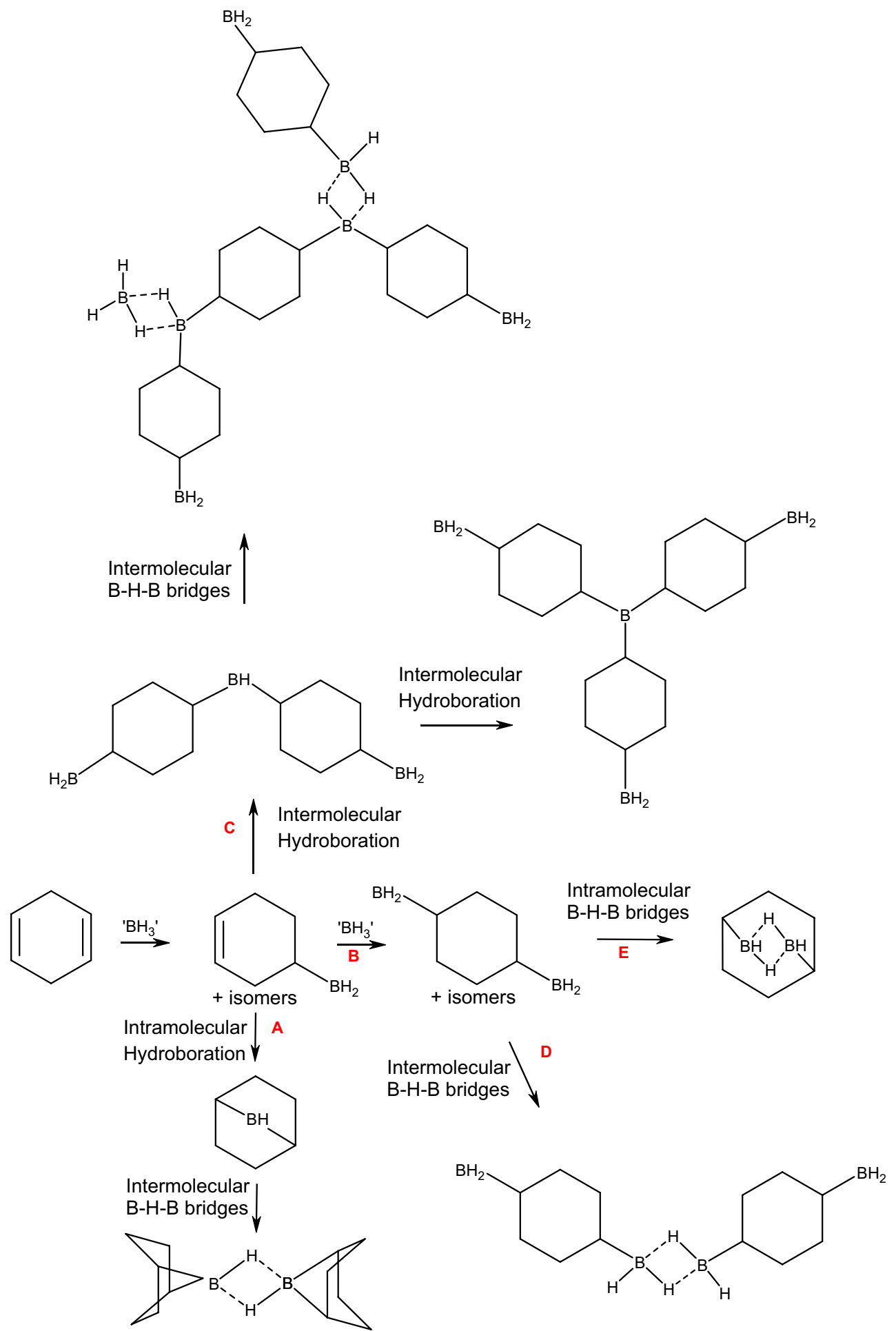

Scheme 2 Schematics of possible reaction intermediates and products in hydroboration reaction pathways utilizing hydroboration of $\mathrm{C}=\mathrm{C}$ double bonds together with $\mathrm{B}-\mathrm{H}-\mathrm{B}$ bridge formation. Pathways

using the high-energy $\mathrm{BH}_{3}$-diene adducts as our starting reactant states [17]. We calculated the energies of geometry-optimized reactant and transition states corresponding
$\mathrm{A}$ or B $+\mathrm{E}$ (red) lead to small-molecule products, whereas pathways $\mathrm{C}$ or $\mathrm{B}+\mathrm{D}($ red $)$ can lead to the formation of polymers

to hydroboration on all possible $s p^{2}$ carbons of the 8 molecules with previously available experimental data [17] from Fig. 1. With the calculated transition state barriers, 
Fig. 1 Schematic and actual optimized molecular structures of the reactant diene molecules considered in this work: 2,3-dimethyl-1,3-butadiene (A4), $\alpha$-terpinene (B6), 1,2,4,5-tetramethyl-1,4-cyclohexadiene (C6), 1,3,5,5-tetramethyl-1,3-cyclohexadiene (D6), 1,5-cyclooctadiene (D8), $\gamma$-terpinene (E6), 1,3-cyclohexadiene (F6), 1,4-cyclohexadiene (G6), 1,3-cyclopentadiene (H5), 1,5,5,6-tetramethyl-1,3-cyclohexadiene (I6a,b), 1,6,6-trimethyl-1,3-cyclohexadiene (J6)
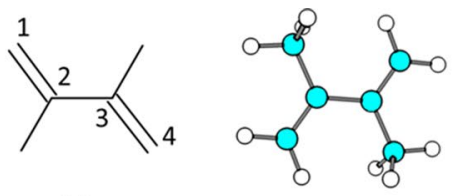

A4

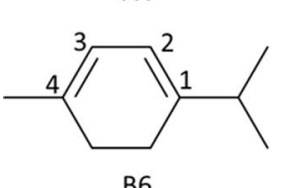

B6<smiles>CC1=C(C)CC(C)=C(C)C1</smiles>

C6<smiles>CC1=CC(C)(C)CC(C)=C1</smiles>

D6<smiles>C1=C[Sn]C=CC1</smiles><smiles>CC1=CC(Br)=CC(C)(C)[C@H]1C</smiles>

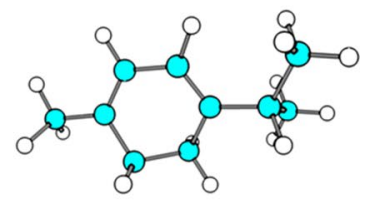<smiles>O=C(O)OC1OB(O)OC(C(=O)O)OC1OC(=O)O</smiles>

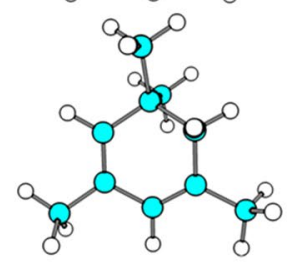<smiles>O=C1OC2OC3OC(O2)C(O)C1O3</smiles>

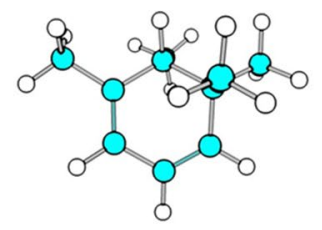
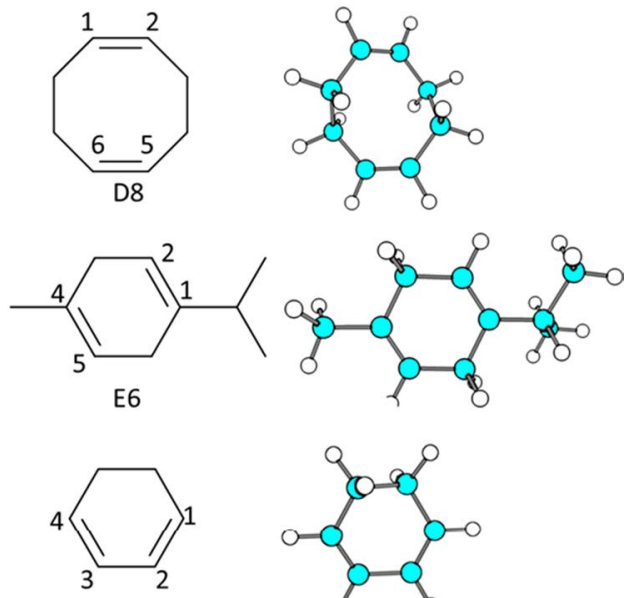

F6<smiles>OC1OC(O)C2OC(O)(OC1O)OC(O)C2O</smiles><smiles>C1=CCC=CC1</smiles>

G6<smiles>O=C1OC2(O)OC(O)C(O)(O1)OC2=O</smiles><smiles>CC1=CC=CCC1(C)C</smiles>

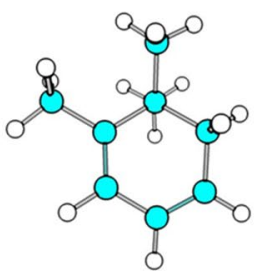<smiles>CC1=CC([18F])=CC(C)(C)C1C</smiles>

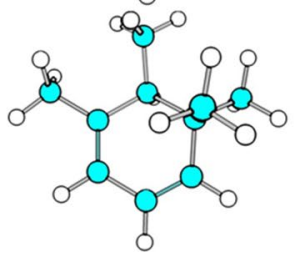

and assuming a kinetically controlled mechanism, we can predict the most favorable isomers computationally [21, 22]. Previous computational studies have also pointed out the fact that the final thermodynamically favored products might not reflect the selectivity of the kinetically favored hydroboration reactions [23] and emphasized the importance of dynamical effects beyond transition state theory [24-26].

The regioselectivity of hydroboration reactions is generally dominated by the anti-Markovnikov product, where boron adds to the least substituted carbon. However, in cyclic dienes, especially those which are symmetrical, the regioselectivity is not immediately obvious owing to the equal number of hydrogens on both sides of the carboncarbon double bond. A key relationship was previously highlighted between the reacting carbon atomic charge and the energy of the intermediates at the transition state [23]. Instead of analyzing the charge distribution of the intermediates, here we hypothesized that the charge density of the reacting dienes would mainly determine the product selectivity, corresponding to the reaction with the lowest transition state barrier. To test this, we calculated the atomic charges of the double-bonded carbon atoms (Figure S1) on the separate reacting molecules without $\mathrm{BH}_{3}$ and compared these to the transition state barriers for each specific hydroboration reaction (Table 1). The calculated free energies using harmonic approximation are consistent with the obtained energy differences and are also reported in Table 1 (in parentheses). We analyzed the results focusing on both (1) the most negative carbons and the corresponding $\mathrm{C}-$ $\mathrm{BH}_{2}$ bond formation and (2) the most positive carbons and the corresponding new $\mathrm{C}-\mathrm{H}$ bond formation.

Our results, presented in Table 1 , were generally consistent with the anti-Markovnikov rule, and the most negatively charged carbon atom afforded the lowest energy transition state (Fig. 3, left). Analogously, the most positive carbon had the lowest energy transition state corresponding to the formation of the new $\mathrm{C}-\mathrm{H}$ bond on that carbon atom 

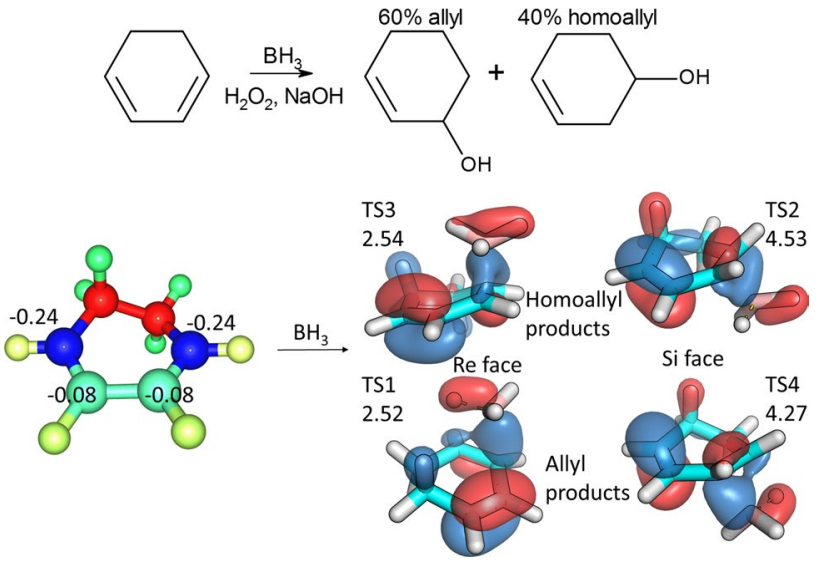

Fig. 2 Top reaction scheme for the hydroboration of 1,3-cyclohexadiene, giving rise to the allyl and homoallyl products. Yields are reported using $\mathrm{B}_{2} \mathrm{H}_{6}$ as the hydroboration agent in THF solvent [20]. Bottom optimized geometries of the F6 molecule and possible transition states leading to regio- and stereoselective monohydroboration intermediates. CHelpG atomic charges of the $s p^{2}$ carbons of the F6 molecule are shown (a.u., color code corresponds to atomic charges), and for each transition state, the HOMO orbitals are displayed together with the corresponding activation energies $(\mathrm{kcal} / \mathrm{mol})$

(Fig. 3, right). Both focusing on the carbon with the $\mathrm{C}-\mathrm{BH}_{2}$ or on the one with the $\mathrm{C}-\mathrm{H}$ bond, the corresponding correlations are very similar and they show a good agreement with the expected selectivity. It is worth noting that the
CHelpG charge scheme [27] performs much more consistently than the Mulliken charge scheme, as expected. The seemingly contradicting atomic charge results between the two schemes can be attributed to the basis set size. CHelpG charges proved to be consistent across smaller $(6-31 \mathrm{G})$ and larger (cc-pVTZ) basis sets for F6 (data not shown). On the other hand, Mulliken charges fluctuated and showed great variations depending on basis set size. In particular, atomic charges of the carbons for A4 are unphysically polarized using diffuse orbitals with the $6-31+\mathrm{G}$ or $6-31+\mathrm{G}^{*}$ basis sets, and the polarization of the $\mathrm{BH}_{3}$ molecule is the opposite of the expected bond polarity using $6-31+\mathrm{G}^{*}$ or cc-pVTZ basis sets (Table S3). The low electronegativity of boron results in the attached hydrogens being more electronegative, allowing the boron to preferentially bond to the most negative conjugated carbon and the hydrogen to bond to the most positive carbon. Interestingly, slightly better correlation is found when considering the positivity of the carbon that forms the new $\mathrm{C}-\mathrm{H}$ bond for B6 molecule (Fig. 3, right); however, the most reactive double bond is also the most polarized bond for all three asymmetric cases (B6, D6, and E6). The correlation with the reactant's atomic charges is less strong considering the prediction for the highest energy transition states, indicating that for the high-energy transition states additional contributing factors are present. None of the highest energy transition states corresponded to the least negative carbon (or least
Table 1 The activation energies (and free energies in parentheses) are given in $\mathrm{kcal} / \mathrm{mol}$ units for the $\mathrm{C}-\mathrm{BH}_{2}$ bond formation for each non-equivalent carbon atom corresponding to the energy difference between the transition state (TS) and the most stable $\mathrm{BH}_{3}$-diene adduct reactant state of the first eight molecules in Fig. 1

\begin{tabular}{|c|c|c|c|c|c|c|}
\hline \multicolumn{2}{|c|}{ Molecule } & \multirow[t]{2}{*}{ Carbon number } & \multicolumn{2}{|c|}{ Atomic charge } & \multicolumn{2}{|c|}{ Activation energy (free energy) } \\
\hline & & & CHelpG & Mulliken & Re face & Si face \\
\hline \multirow[t]{2}{*}{ A4 } & TS1 & 1 & -0.479 & -1.370 & $2.37(2.96)$ & \\
\hline & $\mathrm{TS} 2$ & 2 & 0.149 & 1.078 & $5.56(6.77)$ & \\
\hline \multirow[t]{4}{*}{ B6 } & TS1 & 1 & -0.167 & 0.027 & $7.60(8.51)$ & $7.77(8.48)$ \\
\hline & $\mathrm{TS} 2$ & 4 & 0.082 & 0.015 & $5.08(5.92)$ & $7.51(8.14)$ \\
\hline & $\mathrm{TS} 3$ & 2 & -0.108 & -0.150 & $5.89(6.57)$ & $4.88(5.79)$ \\
\hline & TS4 & 3 & -0.249 & -0.141 & $3.10(3.94)$ & $4.97(5.63)$ \\
\hline C6 & TS1 & 1 & -0.117 & 1.263 & $5.25(6.26)$ & \\
\hline \multirow[t]{4}{*}{ D6 } & TS1 & 2 & -0.354 & -0.322 & $4.40(5.28)$ & $4.76(5.85)$ \\
\hline & $\mathrm{TS} 2$ & 1 & 0.125 & 0.911 & $7.97(8.78)$ & $8.78(9.64)$ \\
\hline & TS3 & 3 & 0.287 & 0.204 & $5.61(6.31)$ & $10.00(10.94)$ \\
\hline & TS4 & 4 & -0.594 & -0.758 & $2.12(2.95)$ & $7.70(8.61)$ \\
\hline \multirow[t]{4}{*}{ E6 } & TS1 & 4 & 0.052 & 0.813 & $5.73(6.47)$ & $5.86(6.20)$ \\
\hline & $\mathrm{TS} 2$ & 5 & -0.387 & -0.190 & $3.25(4.03)$ & $3.30(3.56)$ \\
\hline & TS3 & 1 & -0.175 & 0.186 & $7.96(8.52)$ & $6.23(6.91)$ \\
\hline & TS4 & 2 & -0.302 & 0.398 & $3.87(4.71)$ & $4.37(4.74)$ \\
\hline \multirow[t]{2}{*}{ F6 } & $\mathrm{TS} 1$ & 2 & -0.083 & -0.189 & $2.52(3.39)$ & $4.27(4.98)$ \\
\hline & $\mathrm{TS} 2$ & 1 & -0.243 & -0.007 & $2.54(3.52)$ & $4.53(5.06)$ \\
\hline G6 & TS1 & 1 & -0.256 & 0.093 & $3.25(3.98)$ & \\
\hline
\end{tabular}

Atomic charges (in a.u.) are given for the reacting molecules without $\mathrm{BH}_{3}$ (Figure S1) using both the CHelpG [27] and the Mulliken charge schemes. To assess potential stereospecificity, activation energies were also calculated from Si-face attack leading to enantiomers for B6, D6, E6, and F6 
Fig. 3 Correlation between the carbon atomic charges (a.u.) and the activation energies ( $\mathrm{kcal} / \mathrm{mol}$ ) corresponding to the $\mathrm{C}-\mathrm{BH}_{2}$ (left) and new $\mathrm{C}-\mathrm{H}$ bond formation (right) for B6, D6, and E6 (the lower energy structures are chosen between the Re- and Si-face attack positions)
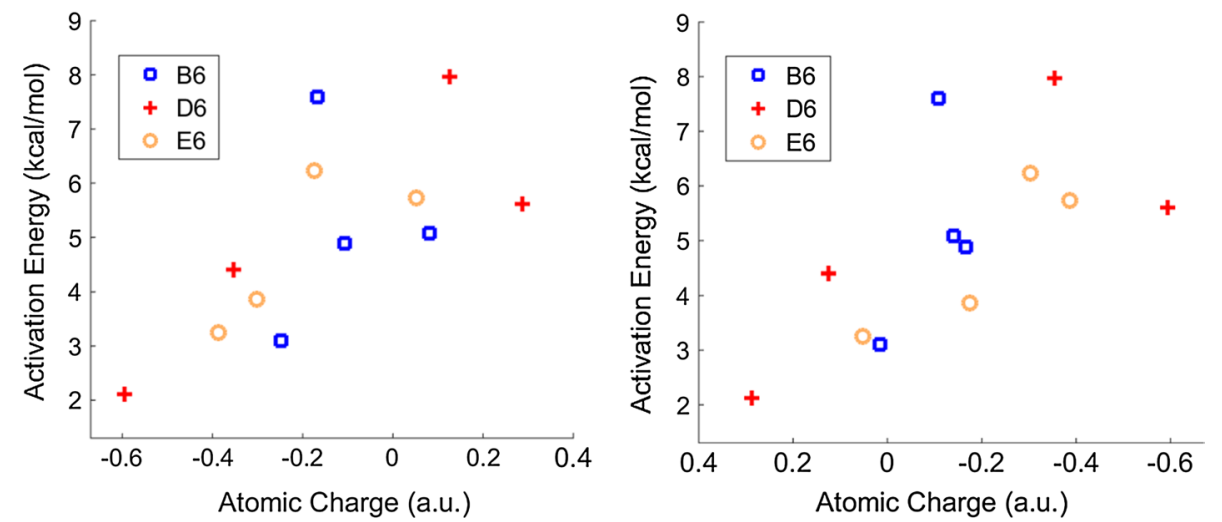

positive, if considering $\mathrm{C}-\mathrm{H}$ bond formation), which might be explained by the more readily available polarization of the double bond with the most negative carbon, to accommodate the TS.

For our first set of 8 molecules corresponding to experimental data, in all but one case, the lowest energy transition state corresponded to the most polarized double bond with the expected selectivity for the hydroboration. Intriguingly, 1,3-cyclohexadiene (F6 molecule) was an exception, despite the strong polarization of the double bonds. The allyl and homoallyl products were approximately equally preferred, with the allyl TS lower in energy by $0.09 \mathrm{kcal} /$ mol based on the larger cc-pVTZ basis set calculations. This agrees well with the experimentally observed slight preference for the allyl product (60-65\%) reported for this molecule using THF as solvent and $\mathrm{B}_{2} \mathrm{H}_{6}$ as hydroboration agent [20]. The experimental selectivity corresponds to a free energy difference of less than $0.4 \mathrm{kcal} / \mathrm{mol}$, which is a difference well within the error of the calculations. Depending on the hydroboration agent, the allyl product can have even higher prevalence over the homoallyl product, with the more positive carbon forming the C-B bond, opposite to other known hydroboration selectivities that follow the anti-Markovnikov rule [19].

According to our calculated TS structures, there was also a strong stereoselectivity of the final products in the $\mathrm{R}$ configuration corresponding to the Re-face attack (Table 1) at both the allyl and homoallyl carbon positions. However, the observed products would be a mixture of enantiomers, as the cyclohexadiene ring would have an equivalent conformer, leading to the opposite selectivity with identical energies. Additional asymmetric substituents at the $\mathrm{CH}_{2}$ groups would likely stabilize one of the two conformers of the ring, leading to stereospecific products.

To quantitatively analyze the energetic and structural reasons for the observed unexpected regioselectivity of F6, we performed separate QM calculations on the cyclohexadiene ring and the $\mathrm{BH}_{3}$ molecules in their respective TS structures. We found that the structural differences were almost negligible for the $\mathrm{BH}_{3}$ molecule and were very minor for the TSs corresponding to the Re-face (TS1 and TS3, RMSD $=0.062 \AA$ ) or the Si-face attacks (TS2 and $\mathrm{TS} 4, \mathrm{RMSD}=0.045 \AA$ ). The main structural changes were due to slight movements of the $\mathrm{CH}_{2}$ groups (Figure $\mathrm{S} 2$ ). The Re- and Si-face attacking direction naturally affects the hydrogen atoms already bonded to the carbons on the double bond, as these carbons move toward $\mathrm{sp}^{3}$ hybridization. We compared the energy differences between the TS geometries and the fully optimized F6 geometry for each TS structure (Table S1; Fig. 4). In general, the allyl and the Re-face attack structures were lower in energy than the homoallyl and the Si-face attack structures, respectively. Consequently, TS1 has the lowest energy, while TS2 the highest. The difference in the relative energies between the $\mathrm{Re}$ - and the Si-face attack structures is likely due to the specific flexibility of the cyclohexadiene ring, with the TS1 and TS3 structures being visibly closer to a chair conformation, whereas TS2 and TS4 are closer to the boat conformation. Interestingly, these minor structural changes lead to significant polarization of the attacked carbon bonds 1 and 2, respectively. In case of TS1 and TS4, the $\mathrm{BH}_{2}$ group attacks at carbon 1 . This carbon also becomes more negative compared to F6, with partial atomic charges changing from -0.08 to -0.18 a.u., for example, for TS1. On the other hand, for TS2 and TS3, the carbon 2 atomic charges change from -0.24 to about -0.32 a.u. These results indicate that the structural changes observed between the allyl and homoallyl intermediates are consistent with the prepolarization of the carbon to allow charge transfer to the positively charged boron at the TS structure. This is also suggested by the displayed HOMO orbitals that are delocalized to the B-H breaking bond in the allyl attack (Fig. 2). In this specific case, the adjacent Lewis base double bond is likely a contributing factor for the preference toward the allyl intermediate.

The paradoxical regioselectivity is often attributed to steric effects of the $\mathrm{CH}_{2}$ groups in the literature [19]. To test whether steric effects might be responsible for the 
Fig. 4 Charge distribution and structures of the cyclohexadiene ring at the TS (color code corresponds to the atomic charges, from blue negative to red positive). The allyl attack conformations pre-polarize the allyl carbon from -0.08 a.u. to about -0.17 a.u., regardless of the attack orientation ( $\mathrm{Re}$ or $\mathrm{Si}$ face). On the other hand, the conformations corresponding to the homoallyl attack prepolarize the homoallyl carbon from -0.24 a.u. to about -0.32 . Relative energies of the F6 molecules are shown in parenthesis ( $\mathrm{kcal} / \mathrm{mol}, \mathrm{red}$ ) compared to the optimized geometry, and arrows indicate the boron attack

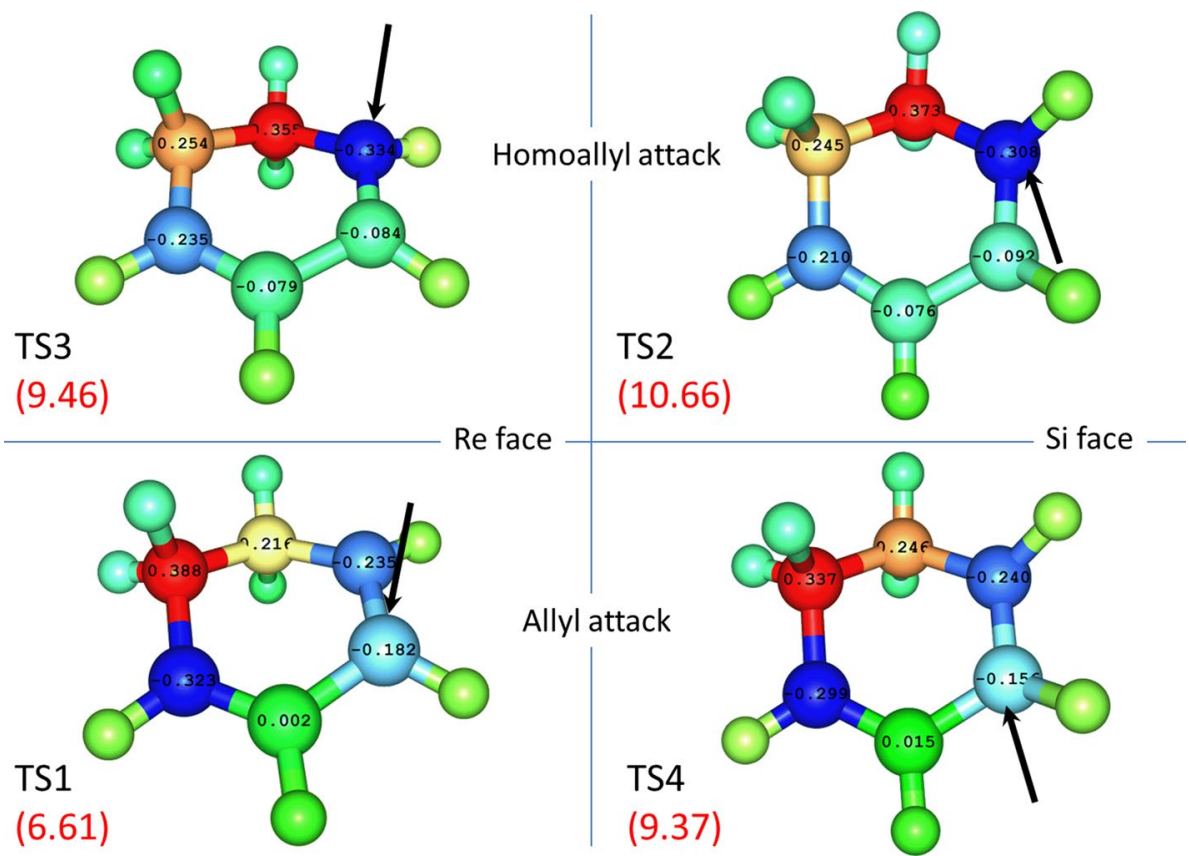

observed energy differences, we analyzed the TS structures with respect to the closest $\mathrm{CH}_{2}-\mathrm{BH}_{3}$ distances (Figure $\mathrm{S} 3$ ). For TS2 and TS4, these distances are as short as $2.30 \AA$. However, there are no significant steric effects between TS1 and TS3 that could prompt the observed energy difference of the F6 geometries ( $6.61 \mathrm{vs.} 9.46 \mathrm{kcal} / \mathrm{mol}$ ). To test this, we reoptimized the TS1 transition state enforcing a fixed distance of $2.38 \AA$ between two hydrogens as shown in Figure S3C, matching the shortest distance present in TS3. The increase in the energy was only $0.2 \mathrm{kcal} / \mathrm{mol}$ for the TS structure and $0.15 \mathrm{kcal} / \mathrm{mol}$ for only the F6 energy without $\mathrm{BH}_{3}$, which does not explain the almost $3 \mathrm{kcal} /$ mol energy difference between the altered $\mathrm{F} 6$ geometries of TS1 and TS3 (Fig. 4). Taken together, the data suggest that the main reason for the structural stabilization energy observed for the allyl attack F6 geometries is due to the differences in polarizability between the allyl and homoallyl positions. Interestingly, we previously reported that when the $\mathrm{BH}_{2}$ substituent is in an axial position, the double bond delocalizes over to the boron dihydride substituent at the allyl position as seen by the HOMO [17] and by the atomic charges (Figure S4). This allyl borane- $\pi$ bond interaction, reminiscent to that of frustrated Lewis pairs [28], imparts a degree of stability to the molecule, through increasing the electron density located at the boron, and contributes to lowering the activation energy of the corresponding transitions states.

To determine the electrostatic and polarization energies between the $\mathrm{F} 6$ and $\mathrm{BH}_{3}$ molecules at the TS structures, we compared the energies of the fully interacting and noninteracting cyclohexadiene and $\mathrm{BH}_{3}$ molecules (Table $\mathrm{S} 1$ ).
The calculated interaction energies show an excellent correlation with the dipole-dipole interactions derived from the parallel $\mathrm{B}-\mathrm{H}$ and $\mathrm{C}=\mathrm{C}$ bonds at the TS (Figure S5). As expected based on the anti-Markovnikov rule, the homoallyl attack corresponds to significantly stronger electrostatic interactions due to the more favorable polarization of the double bond in F6 interacting with the dipole of the B-H bonds at TS3 and TS2.

To further explore examples where the deviation from the anti-Markovnikov rule might be present, we included three additional species in our analysis, described in previous experimental work [18, 29, 30]. Cyclopentadiene (H5) is known to follow the anti-Markovnikov rule, and our calculations also predicted the more favorable homoallyl product [18] both on the basis of the atomic charges of H5 and the calculated activation energies (Table S2). Previous experimental data suggested that 1,5,5,6-tetramethyl-1,3-cyclohexadiene (I6a,b), 1,6,6-trimethyl-1,3-cyclohexadiene (J6) can favor the allyl product under some conditions. For both of these molecules, the most polarized double bond corresponds to carbons 3 and 4, with carbons 1 and 3 being the most positively charged $s p^{2}$ carbons (Table S2). According to the anti-Markovnikov rule, we would expect the homoallyl carbon 4 to be most likely substituted by the $\mathrm{BH}_{2}$ substituent after hydroboration. The activation energies suggest, however, that there is a nearly equal amount of allyl (I6a TS1 and I6b TS3 in total) and homoallyl (I6b TS4) products for I6 at carbons 3 and 4, respectively. Here, the unexpected preference for the positively charged carbon 3 is likely compensated for by the highly polarized double bond and by the conjugation also 
observed in F6. In J6, the most preferred substitution corresponds to carbon 2 according to our calculations, favoring the allyl position, and the most negatively charged homoallyl carbon 4 is less preferred with a higher activation energy.

In summary, our results show that the regioselectivity can be attributed to the interplay between two main factors (1) the dipole-dipole interactions of the boron B-H bond with the double bond and (2) the allyl position of a second double bond providing favorable polarization in the sixmembered ring. In addition, the stereoselectivity is largely controlled by the structural flexibility of the cyclohexene ring favoring the Re attack.

These results lend themselves to predicting the most likely product of hydroboration reactions, as the molecule with the lowest energy transition state should yield the kinetic product. These results are also in correlation with the anti-Markovnikov regioselectivity of the reaction: the electropositive boron within a hydrogen-boron bond of the borane electrostatically favors the most negatively charged $s p^{2}$ carbon within the molecule. Intriguingly, 1,3-cyclohexadiene presents an important exception to the anti-Markovnikov rule, whereas transition state theory continues to predict the selectivity of the reaction.

The observed product specificity does depend not only on the selectivity of the first hydroboration step leading to monosubstituted $\mathrm{RBH}_{2}$ compounds, but also on subsequent hydroboration reactions as well. We showed previously that the $\mathrm{RBH}_{2}$ products can be more reactive than the borane, and we expect rapid formation of $\mathrm{R}_{2} \mathrm{BH}$ products [17]. We assumed here that the selectivity remains similar using $\mathrm{RBH}_{2}$ for hydroboration; however, future studies aiming for fully quantitative results would need to take into account subsequent steps. Here we further analyzed the possible hydroboration products after the completion of the hydroboration reactions.

\subsection{Full hydroboration products of dienes}

To better understand the nature of final hydroboration products before subsequent oxidation, we considered competing pathways of hydroboration reactions (Scheme 2). The end product of the first hydroboration step using an activated ' $\mathrm{BH}_{3}$ ' is a mixture of monosubstituted boranes with a single double bond. Further borane addition can take place in three different ways: by intermolecular hydroboration via the attached $\mathrm{BH}_{2}$ substituent (pathway $\mathrm{A}$ in Scheme 2), by another activated ' $\mathrm{BH}_{3}$ ' molecule (pathway $\mathrm{B}$ in Scheme 2), or by intramolecular hydroboration via another monosubstituted borane (pathway $\mathrm{C}$ in Scheme 2). Covalent polymers can thus form via pathway C [17], following the intermolecular hydroboration reaction pathway. In pathway $\mathrm{C}$, subsequent hydroboration of $\mathrm{R}_{2} \mathrm{BH}$ species can further occur to form trialkyl boranes. Accordingly, well-documented examples suggest that the corresponding species are often found as homologues of trialkylboranes $\left(\mathrm{R}_{3} \mathrm{~B}\right)$ [20, 31].

Immediately following the hydroboration reactions, the high-energy trigonal boron species are stabilized by forming intermolecular (e.g., via pathway D) or intramolecular (when possible, e.g., via pathway E) B-H-B bridges. Stabilization can also occur via adduct formation with the solvent or with $\mathrm{BH}_{3}$. Trialkyl species are exceptions, in that they are generally stable trigonal boron species that do not form adducts [17].

In Scheme 2, dimeric or monomeric small-molecule compounds form via pathways $\mathrm{A}$ and $\mathrm{B}+\mathrm{E}$. On the other hand, polymers may form via pathways $\mathrm{C}$ or $\mathrm{B}+\mathrm{D}$. Here we aimed to compare the $\mathrm{A}$ and $\mathrm{B}+\mathrm{E}$ pathways and to verify whether the species are also observed experimentally, and to infer their relative prevalence.

In hydroboration reactions described in our previous study [17], two possible products were observed depending on the nature of the reactant dienes and the reaction conditions: formation of cross-linked polymers, which precipitate out of solution, or formation of soluble, smallmolecule products, which have been analyzed using ${ }^{11} \mathrm{~B}$ NMR. Previous analysis [17] of the experimental NMR data (reproduced here as Figs. 5 and S6) suggested that a range of fully hydroborated product species were present. The substrates F6, 1,3-cycloheptadiene, 1,3-cyclooctadiene, G6, and E6 all yielded cross-linked polymers, whereas substrates D8, B6, C6, and the control A4 all yielded clear solutions. Interestingly, the excess equivalents of borane used in the reaction can also affect the outcome of the reaction products for certain molecules, such as in the example of 1,3,5,5-tetramethyl-1,3-cyclohexadiene (D6), which was seen to form a clear solution when only one equivalent of borane was used, but an insoluble precipitate was observed when two equivalents were used [17]. The clear solution of D6 eventually formed a precipitate after $2 \mathrm{~h}$.

${ }^{11} \mathrm{~B}$ NMR of the clear solutions of substrates reacted with two equivalents of borane resulted in spectra with many peaks, the origins of which were not all apparent. The presence of peaks at -10.4 and -29.1 ppm was attributed to the presence of impurities in the $\mathrm{BH}_{3} \cdot \mathrm{SMe}_{2}$ starting material, but were found not to participate in the hydroboration reaction. The presence of a quartet at $-20.4 \mathrm{ppm}$ was due to unreacted $\mathrm{BH}_{3} \cdot \mathrm{SMe}_{2}$. The main experimental peaks of the hydroboration products are listed in Table 2 together with initial assignment of the corresponding species [32]. In this work, we calculated theoretical chemical shifts for possible reaction products (Table S4) through the use of quantum chemical calculations, and their concordance with reported experimental data was compared. 
Fig. $5{ }^{11} \mathrm{~B}$ NMR spectra at one equivalent $\mathrm{BH}_{3} \cdot \mathrm{SMe}_{2}$. The ${ }^{11} \mathrm{~B}$ NMR spectra of the clear solutions after hydroboration of (from bottom to top) $\alpha$-terpinene (B6), 1,3,5,5-tetramethyl-1,3-cyclohexadiene (D6), 2,3-dimethyl-1,3-butadiene (A4), 1,2,4,5-tetramethyl1,4-cyclohexadiene (C6), and 1,5-cyclooctadiene (D8) in diglyme. Diagram adapted from Andreou et al. [17]

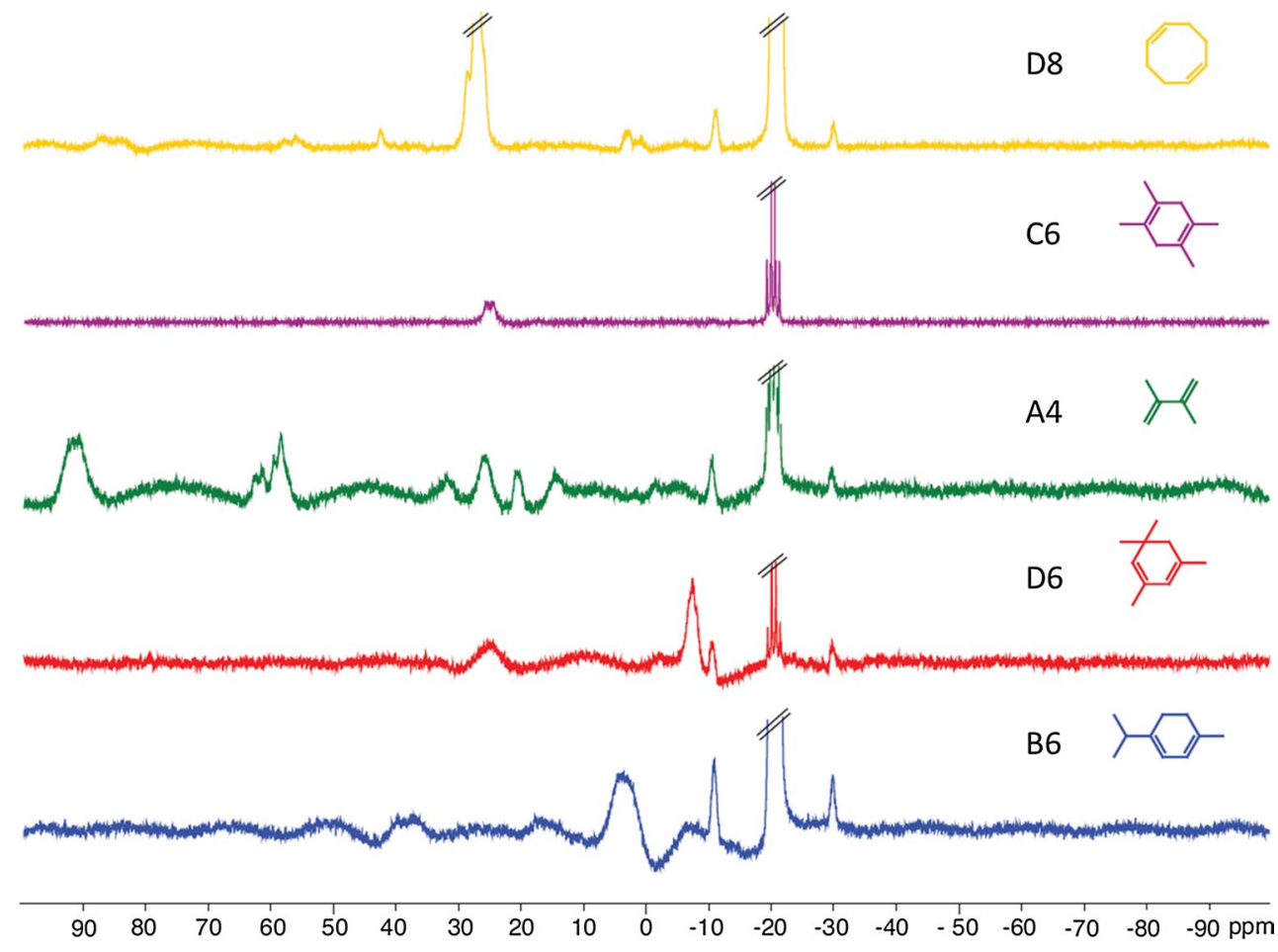

The competing reaction pathways during hydroboration have very different rates depending on the chemical structure of the diene, thus resulting in entirely different outcomes. Previous work by Brown and Bhat [18] suggested that monohydroboration was prevalent in six-membered rings, which were thought to be relatively inert to dihydroboration. Our recent work has shown that with sufficient excess borane using either $\mathrm{B}_{2} \mathrm{H}_{6}$ or $\mathrm{BH}_{3} \cdot \mathrm{SMe}_{2}$, all cyclic dienes undergo complete hydroboration of all double bonds [17].

As evident, a large number of ${ }^{11} \mathrm{~B}$ NMR peaks in Table 2 for the first hydroboration products can be attributed to the formation of intermolecular B-H-B-bridged compounds, such as $\mathrm{R}_{2} \mathrm{BHBH}_{3}$. Interestingly, however, in the characterization of the direct products of diene hydroboration, the possibility of intermolecular hydroboration via $\mathrm{RBH}_{2}$ species and the role of pathway $\mathrm{C}$ are often omitted in theoretical calculations. In Table 1, we also focused on the reactions with $\mathrm{BH}_{3}$ as the hydroboration agent; however, we note that to quantitatively account for the selectivity, subsequent reactions also need to be taken into account where $\mathrm{RBH}_{2}$ species serve as hydroboration agents. Toward this aim, here we investigate a second, intramolecular dihydroboration step of pathway A, leading to bridged bicyclic rings.

Pathway A with intramolecular hydroboration is favored for dienes where the double bonds are farther apart, hence the rapid dihydroboration of the 1,5-cyclooctadiene [19]. On the other hand, molecules such as 1,3-cyclooctadiene and 1,3-cycloheptadiene were seen to polymerize following pathway $\mathrm{B}$ or $\mathrm{C}$, and only the 1,5-cyclooctadiene was observed to yield clear solution. Therefore, with six-membered or larger rings, the intramolecular hydroboration will occur dominantly when the double bonds are not in proximity to each another [18]; otherwise, steric constraints take precedence and the cyclic product does not rapidly form. With smaller rings, the energy barrier to form cyclic products is higher, and pathways A and B can be in competition with one another.

To better understand the structures and energetics of the mechanism for reaction pathway A, we performed initial reaction coordinate scanning using the $\mathrm{B}-\mathrm{C}$ bond distance as the reaction coordinate with ORCA and calculated the energy profiles for A4 and D8 molecules (Figure S7, top). Subsequently, we optimized the TS geometries using Gaussian 09 (Fig. 6, and Figure S7, bottom). To ensure that the correct saddle point was identified, we calculated the minimum energy reaction pathway using the intrinsic reaction coordinate (IRC) [33] with Gaussian 09 (Fig. 6, left).

The calculated energy barrier starting with the monohydroborated D8 1,5-cyclooctadiene was $8.25 \mathrm{kcal} / \mathrm{mol}$, which is easily overcome in room temperature, and therefore, a rapid reaction is expected. Note, however, that to determine the actual activation energies, the relative energy of the reactant states also needs to be accounted for, as B-H-B bridges are generally more stable than the interacting intramolecular $\pi$-bond-borane adduct [17]. We have not calculated this here, but estimate it to be below $7 \mathrm{kcal} /$ 
Table 2 Experimental ${ }^{11} \mathrm{~B}$ NMR chemical shifts in THF and diglyme, their structural attributions, and calculated chemical shifts

\begin{tabular}{|c|c|c|c|}
\hline \multirow[t]{2}{*}{ Reactant molecule } & \multicolumn{2}{|c|}{ Exp. ${ }^{11} \mathrm{~B}$ NMR } & \multirow[t]{2}{*}{ Attribution } \\
\hline & THF & diglyme & \\
\hline \multirow[t]{2}{*}{ B6 } & 4.7 & 4.9 & $\mathrm{R}_{2} \mathrm{BHBH}_{3}$ \\
\hline & 40.8 & 40.0 & $\mathrm{R}_{2} \mathrm{BHBH}_{3}$ \\
\hline \multirow[t]{2}{*}{ D6 } & -6.9 & -7.1 & $\mathrm{RBH}_{2} \cdot \mathrm{SMe}_{2}$ \\
\hline & 26.0 & 25.0 & $\left(\mathrm{RBH}_{2}\right)_{2}$ \\
\hline \multirow[t]{7}{*}{ A4 } & 14.7 & 14.9 & $\mathrm{R}_{2} \mathrm{BHBH}_{2} \mathrm{R}$ \\
\hline & 21.3 & 21.1 & $\left(\mathrm{RBH}_{2}\right)_{2}$ \\
\hline & 26.6 & 26.1 & $\left(\mathrm{R}_{2} \mathrm{BH}\right)_{2}$ \\
\hline & 32.1 & 32.4 & $\mathrm{R}_{2} \mathrm{BHBH}_{2} \mathrm{R}$ \\
\hline & 58.7 & 58.8 & N/A \\
\hline & 60 & 60 & N/A \\
\hline & 91.5 & 91.2 & $\mathrm{R}_{3} \mathrm{~B}$ \\
\hline \multirow[t]{3}{*}{ C6 } & 24.8 & 26.0 & $\left(\mathrm{R}_{2} \mathrm{BH}\right)_{2}$ \\
\hline & 17.8 & 17.7 & \\
\hline & -12.9 & & \\
\hline \multirow[t]{9}{*}{ D8 } & 8.5 & 1.4 & $\mathrm{R}_{2} \mathrm{BHBH}_{3}$ \\
\hline & & 3.7 & \\
\hline & 18.5 & 13.4 & N/A \\
\hline & 27.6 & 27.6 & Cyclic $\left(\mathrm{R}_{2} \mathrm{BH}\right)_{2}$ \\
\hline & & 29.1 & \\
\hline & 43.0 & 43.0 & $\mathrm{R}_{2} \mathrm{BHBH}_{3}$ \\
\hline & & 56.7 & \\
\hline & 84.8 & 88.3 & $\mathrm{R}_{3} \mathrm{~B}$ \\
\hline & 87.6 & & $\mathrm{R}_{3} \mathrm{~B}$ \\
\hline
\end{tabular}

The chemical shifts of the most prominent peaks are highlighted in bold. Corresponding calculated potential structures are available in SI (Table S4)

mol based on calculations presented in Table S1 of Andreou et al. [17], resulting in an overall barrier below $15 \mathrm{kcal} / \mathrm{mol}$. The dihydroborated D8 product species affords a bicyclic ring system consisting of two six-membered rings. Figure 6 illustrates that a stable reactant complex is formed via the intramolecular borane adduct formation, and the reaction proceeds via a relatively sharp transition state, corresponding likely to the simultaneous breaking and forming of rigid hydrogen bonds (B-H and $\mathrm{C}-\mathrm{H})$ at the TS. In a solution where borane is not readily available, this secondary intramolecular hydroboration step would be even faster due to the availability of the already activated $\mathrm{RBH}_{2}$ species, in particular where $\mathrm{BH}_{2}$ does not yet form stable $\mathrm{B}-\mathrm{H}-\mathrm{B}$ bridges, only adducts with the solvent.

In contrast to D8, the intramolecular dihydroboration step of monohydroborated A4 has an increased barrier of $15.04 \mathrm{kcal} / \mathrm{mol}$. This is largely due to the steric strains due to the smaller alkyl chain, as seen from the unusual intramolecular adduct reactant state structure (A4 RS in Fig. 6). Cyclic dienes with 6-membered rings are expected to have further steric constraints to the barrier of the intramolecular dihydroboration. Accordingly, we obtained a $16.17 \mathrm{kcal} /$ mol activation barrier for C6 (Figure S7), a slight increase from that of the A4 molecule. To consider entropic effects at the harmonic approximation, we also calculated the zero point energies and determined the corresponding activation free energies. Entropic effects generally render the barriers higher as shown also in Table 1 . The difference is particularly significant for A4 $(17.88 \mathrm{kcal} / \mathrm{mol})$, whereas C6 $(17.04 \mathrm{kcal} / \mathrm{mol})$ and D8 $(8.58 \mathrm{kcal} / \mathrm{mol})$ have only a relatively small increase between activation energies and activation free energies.

Subsequently, we calculated the ${ }^{11} \mathrm{~B}$ NMR chemical shifts both for the dimeric cyclic disubstituted boranes obtained via pathway A followed by dimerization and for the intramolecular B-H-B-bridging diborane compounds obtained via pathway $\mathrm{B}+\mathrm{E}$ (Table 3). The calculated chemical shifts are listed alongside the experimental values in the range of +20 to $+30 \mathrm{ppm}$ (Table 3 ). The difficulties in assigning chemical shifts to specific species arose due to the $\pm 2 \mathrm{ppm}$ error margin of both theoretical and experimental data. Despite this, many peaks were possible to assign accurately. In the case of D8, the expected
Fig. 6 Reactant intermediate and transition state species of A4 (top right) and D8 (bottom right) for intramolecular dihydroboration. Reaction energy profiles were determined by IRC calculations [33] for A4, D8, and C6 (left). Geometryoptimized reactant and product states provided activation (free) energies of $15.04 \mathrm{kcal} /$ $\mathrm{mol}(17.88 \mathrm{kcal} / \mathrm{mol})$ for A4, $8.25 \mathrm{kcal} / \mathrm{mol}(8.58 \mathrm{kcal} / \mathrm{mol})$ for $\mathrm{D} 8$, and $16.17 \mathrm{kcal} / \mathrm{mol}$ (17.04 kcal/mol) for C6
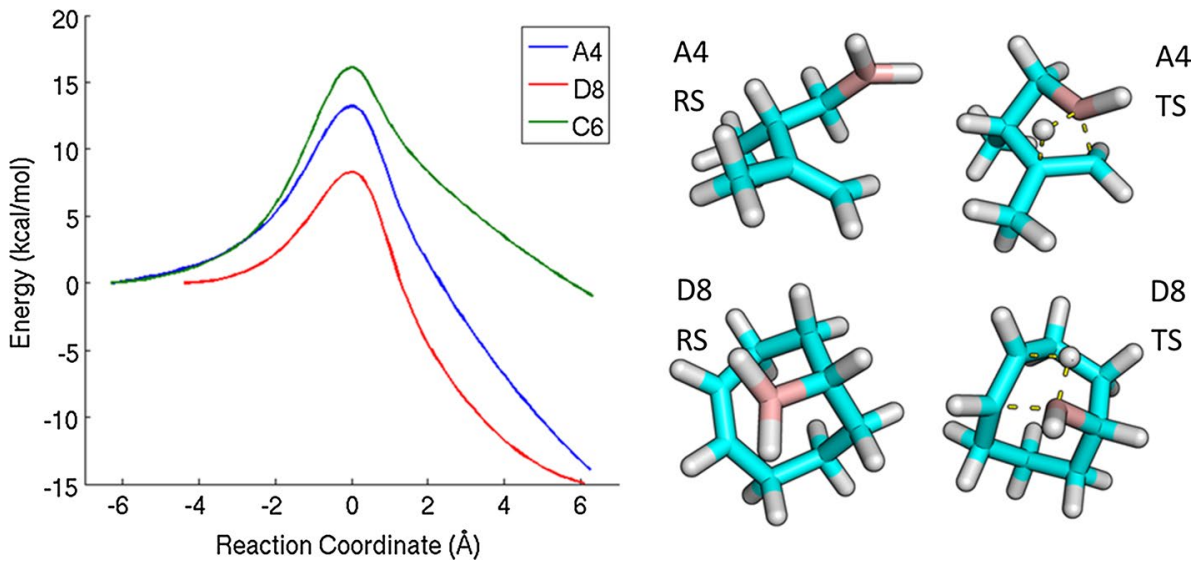
Table 3 Calculated NMR chemical shifts (ppm) of dimeric cyclic boranes and intramolecular $\mathrm{B}-\mathrm{H}-\mathrm{B}$-bridging diborane

\begin{tabular}{llll}
\hline & Cyclic $\left(\mathrm{R}_{2} \mathrm{BH}_{2}\right)_{2}$ & Intramolecular $\left(\mathrm{RBH}_{2}\right)_{2}$ & Exp. \\
\hline A4 & 28.7 & 19.5 & $21.3,26.6$ \\
B6 & 23.6 & $25.2,25.6$ & N/A \\
C6 & 26.5 & 23.8 & $25.0-26.0$ \\
D6 & 22.4 & $19.3,24.0$ & $25.0-26.0$ \\
D8 & 26.7 & 23.3 & 27.6 \\
\hline
\end{tabular}

Experimentally observed peaks close to the calculated chemical shifts are also given
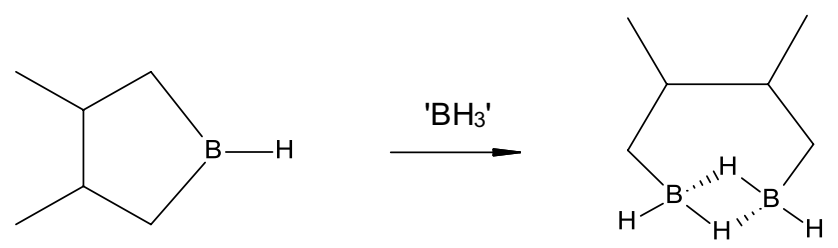

Scheme 3 Breaking of the borolane ring upon further addition of borane, $\mathrm{BH}_{3}$, to form a diborane $\mathrm{A} 4$ species

cyclic products are formed at the calculated $+26.7 \mathrm{ppm}$, and the diborane species are not observed. On the other hand, A4 appears to have both kinds of molecules. The diborane species at $+19.5 \mathrm{ppm}$ matches the experimental value of $+21.3 \mathrm{ppm}$ well. The assignment of the cyclic products at the calculated $+28.7 \mathrm{ppm}$, however, is less certain considering other potential species that might account for the observed peak at $+26.6 \mathrm{ppm}$. In general, the chemical shifts of the diborane and cyclic dimer species are very similar for B6, C6, and D6, and their assignment cannot be done without ambiguity. Interestingly, all molecules exhibit strong peaks at the +20 to $+30 \mathrm{ppm}$ region and likely contain at least one of the species considered in Table 3, except for B6. The NMR spectrum of B6 is significantly different from all other species, and the predicted $\mathrm{R}_{2} \mathrm{BH}$ species in the $\mathrm{R}_{2} \mathrm{BHBH}_{3}$ remains elusive.

Experimentally, monosubstituted and unbridged disubstituted products are commonly accepted, and the formation of cyclic disubstituted products is thought to be more limited to larger cyclic dienes or longer alkyl chains [18]. The explanation underpinning this can be partly due to the strained geometries of the cyclic transition states, such as that for A4 (Fig. 6), and this can result in further ring-opening reactions with $\mathrm{BH}_{3}$ as proposed earlier via a hydrogenalkyl exchange mechanism (Scheme 3) [15, 34, 35]. Analogously, we found that the A4.6 (Table S3) species with $+22.42 \mathrm{ppm}$ calculated chemical shift has a lower energy by $4.85 \mathrm{kcal} / \mathrm{mol}$ compared with the $\mathrm{A} 4.5$ cyclic $\left(\mathrm{R}_{2} \mathrm{BH}_{2}\right)_{2}$ species and might correspond to the observed peak at $+21.07 \mathrm{ppm}$. On the other hand, the corresponding cyclic diene derivatives were less energetically favorable for C6 (data not shown), D6 (D6.5 vs D6.4 in Table S3), and D8 (D8.2 vs D8.6 in Table S3).

Figure 5 and S6 of one and two equivalents of borane, respectively, show highly similar spectra for most molecules. The largest differences are observed in the case of $\mathrm{A} 4$, which showed products of the form $\left(\mathrm{RBH}_{2}\right)_{2}$ and $\left(\mathrm{R}_{2} \mathrm{BH}\right)_{2}$ become the major products when two borane equivalents are used. This suggests that these peaks do not correspond to the cyclic $\left(\mathrm{R}_{2} \mathrm{BH}_{2}\right)_{2}$ species, as these would be expected to become less prominent when borane is in excess due to ring-opening reactions. Analogously, this decrease is observed for D8, where the borane excess enhances minor peaks, and the main peak is visibly reduced. Interestingly, precipitate formation was also observed for D8 almost instantly when two equivalents of borane were used, analogously to D6 [32]. The excess equivalents of borane via the ring-opening reactions thus might contribute to polymer formation.

\section{Methodology}

All calculations were performed and completed using the Gaussian 09 and ORCA suites of programs [36, 37]. Geometry optimizations of the reactant and transition states were done at the B3LYP level of theory with the $6-31+\mathrm{G}(\mathrm{d}, \mathrm{p})$ basis set [38] and the GD3 empirical dispersion correction [39] for each reported molecule using Gaussian 09. To determine the reaction profiles for intramolecular hydroboration, initial relaxed surface scans were performed with ORCA along the B-C bond distance of the A4, C6, and D8 molecules at $0.05 \AA$ increments, using density functional theory methods as described above. The identified transition and product states were then fully optimized using Gaussian 09, and subsequent IRC calculations [33] were performed to confirm the RS and PS states corresponding to the TS structures identified. Vibrational frequencies were calculated for all optimized geometries to confirm the identity of each state using Gaussian 09.

The CHelpG population analysis method implemented in Gaussian 09 was used to calculate Merz-Kollman atomic charges $[27,40]$ for each atom within the optimized diene reactant states as described above.

Theoretical predictions for the NMR chemical shifts of the hydroboration products were done using optimized geometries obtained as described above. Single-point calculations were performed employing a larger basis set, 6-311+G(d,p), to determine the NMR shielding tensors using the Gaussian implementation of the gauge-independent atomic orbital (GIAO) method developed by Pulay et al. [41]. 
All previous experimental ${ }^{11} \mathrm{~B}$ NMR work was carried out by Andreou et al. in both THF and bis(2-methoxyethyl)ether (diglyme) solvents [17, 32]. THF solvent was purchased from Acros, diglyme from Sigma-Aldrich, and deuterated NMR solvents from Euriso-top. ${ }^{11} \mathrm{~B}$ NMR spectra were carried out using a Bruker Advance BBATM-500 MHz NMR spectrometer using $\mathrm{BF}_{3} \cdot \mathrm{OEt}_{2}$ as a reference.

Experimental work involved the following dienes: $\alpha$-terpinene $(0.12 \mathrm{~mL}, \quad 0.7340 \mathrm{mmol}), \quad \gamma$-terpinene $(0.12 \mathrm{~mL}, \quad 0.7340 \mathrm{mmol}), \quad$ 1,3-cyclohexadiene $(0.07 \mathrm{~mL}, 0.7340 \mathrm{mmol}), 1,3$-cyclooctadiene $(0.09 \mathrm{~mL}$, $0.7340 \mathrm{mmol}), \quad$ 1,3,5,5-tetramethyl-1,3-cyclohexadiene $(0.13 \mathrm{~mL}, 0.7340 \mathrm{mmol}), 1,2,4,5$-tetramethyl-1,4-cyclohexadiene $(0.1 \mathrm{~g}, 0.7340 \mathrm{mmol}), 1,5$-cyclooctadiene $(0.12 \mathrm{~mL}$, $0.7340 \mathrm{mmol}), 2,3$-dimethyl-1,3-butadiene $(0.09 \mathrm{~mL}$, $0.7340 \mathrm{mmol}$ ).

In THF, the representative procedure for the hydroboration of dienes used $\mathrm{BH}_{3} \cdot \mathrm{SMe}_{2}$, utilizing the borane to diene addition mode: $\mathrm{BH}_{3} \cdot \mathrm{SMe}_{2}(0.14 \mathrm{~mL}, 1.4680 \mathrm{mmol})$ was added dropwise to a solution of a diene dissolved in THF $(1 \mathrm{~mL})$ pre-cooled to $-40{ }^{\circ} \mathrm{C}$. The reaction mixture was left to stir under nitrogen at $0{ }^{\circ} \mathrm{C}$ for $1 \mathrm{~h}$ to give a clear solution, which, depending on the diene used, contained a white precipitate.

In diglyme, the representative procedure for the hydroboration of dienes used $\mathrm{BH}_{3} \cdot \mathrm{SMe}_{2}$, utilizing the borane to diene addition mode: $\mathrm{BH}_{3} \cdot \mathrm{SMe}_{2}(0.07 \mathrm{~mL}, 0.7340 \mathrm{mmol}$ or $0.14 \mathrm{~mL}, 1.4680 \mathrm{mmol}$ ) was added dropwise to a solution of a diene dissolved in diglyme $(3.2 \mathrm{~mL})$. The reaction mixture was left to stir under nitrogen at $0{ }^{\circ} \mathrm{C}$ for $1 \mathrm{~h}$ to give a clear solution, which, depending on the diene used, contained a white precipitate.

\section{Conclusions}

Hydroboration is one of the most valuable chemical synthesis methods, due to many reasons, including its highly specific regio- and stereoselectivity. However, in complex reagents, the identity of the preferred anti-Markovnikov product is not apparent at first glance. The use of electrostatic potential-based atomic charges has proved to be a useful tool in predicting the regioselectivity of hydroboration reactions. Here we studied 11 molecules, representing 10 cyclic dienes and a straight chain diene. In most examples, the regioselectivity for the preferred product was predicted both by the extended anti-Markovnikov rule, using the atomic charges of the reactants, and also by transition state theory-comparing the activation energies of all possible products. Here we identified the 1,3-cyclohexadiene molecule as a key exception to the anti-Markovnikov rule, which had an unforeseen preference toward the allyl product according to the transition state barrier heights. Our calculated activation energies accurately predicted the selectivity favoring almost equally the allyl products, in agreement with previous experimental studies [19], therefore validating our transition state theory-based calculation results. The unexpected selectivity was suggested to arise due to steric effects [19]. We found, however, that steric effects do not directly contribute to the observed selectivity, leading to a deviation from the anti-Markovnikov rule. Instead, the stability of the axial $\mathrm{BH}_{2}$ group via conjugation with the allyl double bond is a more important stabilizing factor, which also relies on the unique structural properties of the cyclohexene ring as additional required factors for the paradoxical regioselectivity. We also introduced two additional derivatives (I6 and J6) and confirmed the similar selectivity rules favoring allyl positions for these molecules as well. These molecules lend themselves as additional examples with exceptional regioselectivity against the antiMarkovnikov rule.

As the anti-Markovnikov rule follows the same general principle as the Markovnikov rule [23] in terms of the most energetically favorable reaction pathway being determined by the attractive dipole-dipole interactions within a carbon-carbon double bond and the reacting $\mathrm{X}-\mathrm{H}$ substituent, our results therefore provide an exception (on the basis of F6, I6, and J6) to these rules in general. We found that the Lewis acid borane, and the second remaining double bond with Lewis base properties, resembling frustrated Lewis pair-type moieties, worked synergistically to stabilize allyl $-\pi$ bond interactions resulting in the unexpected selectivity. Using this as a design principle, molecules with similar electronic properties might provide an interesting avenue for the exploration of synthetically useful exceptions to the Markovnikov rule, resulting in novel chemical reactivity.

Although it is known that the process of hydroboration can occur fully at all unsaturated sites within an alkene, the precise nature of the unoxidized species formed after the completion of the reactions still remains within a gray area.

${ }^{11} \mathrm{~B}$ NMR results show that several hydroboration reactions are possible, and that a variety of products may be formed.

Quantum chemical calculations together with NMR measurements can thus shed light on why a subset of reactants does not polymerize, while others do, and what the potential reaction pathways and stable products are. The observation of a plethora of products indicates that competing pathways concurrently take place within hydroboration reactions. It was concluded that the position of the double bonds, in relation to sterically demanding groups, was a strongly influencing factor in determining the structure of the product [17]. We have elucidated the mechanism for the formation of cyclic monohydroborated species, as well as specific diborane species. Our results are in very 
good agreement with experimental ${ }^{11} \mathrm{~B}$ chemical shifts; thus, computational methods can unveil detailed mechanistic hydroboration pathways and accurately predict the NMR peaks of specific products, verifying the reaction mechanism.

Studying the experimental conditions necessary to secure a specific product would prove to be an interesting avenue of research to pursue, as current procedures allow for the possibility of multiple product species, such as dimers, polymers, and oligomeric species. Quantum chemical calculations thus lend themselves as useful tools to help design novel enantio- and diastereoselective chemical synthesis strategies. They are also becoming easily available standard tools that are accessible in undergraduate education for computational laboratories.

Acknowledgments LH was supported by the King's Undergraduate Research Fellowships. ER gratefully acknowledges Péter Surján and the inspiration she received from the undergraduate research in his laboratory, leading to her first papers. Péter continues to inspire her work through research and teaching, including this study that was carried out together with undergraduate students at King's College, London.

Open Access This article is distributed under the terms of the Creative Commons Attribution 4.0 International License (http://creativecommons.org/licenses/by/4.0/), which permits unrestricted use, distribution, and reproduction in any medium, provided you give appropriate credit to the original author(s) and the source, provide a link to the Creative Commons license, and indicate if changes were made.

\section{References}

1. Yang DT, Mellerup SK, Wang X, Lu JS, Wang SN (2015) Reversible 1,1-hydroboration: boryl Insertion into a $\mathrm{C}-\mathrm{N}$ Bond and competitive elimination of HBR2 or R-H. Angew Chem Int Ed 54(18):5498-5501. doi:10.1002/anie.201500487

2. Fan XT, Zheng JH, Li ZH, Wang HD (2015) Organoborane catalyzed regioselective 1,4-hydroboration of pyridines. J Am Chem Soc 137(15):4916-4919. doi:10.1021/jacs.5b03147

3. Chong CC, Hirao H, Kinjo R (2015) Metal-free sigma-bond metathesis in 1,3,2-diazaphospholene-catalyzed hydroboration of carbonyl compounds. Angew Chem Int Ed 54(1):190-194. doi:10.1002/anie.201408760

4. Taniguchi T, Curran DP (2014) Hydroboration of arynes with N-heterocyclic carbene boranes. Angew Chem Int Ed 53(48):13150-13154. doi:10.1002/anie.201408345

5. Sztáray B, Rosta E, Böcskey Z, Szepes L (1999) Geometry and electronic structure of bis(tetrahydridoborato) bis(cyclopentadienyl)zirconium(IV). J Organomet Chem 582(2):267-272. doi:10.1016/S0022-328X(99)00062-5

6. Suzuki A (2010) Organoboranes in organic synthesis including suzuki coupling reactions. Jpn Inst Heterocycl Chem 80(1):1543. doi:10.3987/COM-09-S(S)Summary

7. Allais C, Tsai AS, Nuhant P, Roush WR (2013) Highly diastereo- and enantioselective aldol reactions of stereochemically defined tetrasubstituted enolborinates generated by 1,4-hydroboration of $\alpha, \beta$-unsaturated morpholine carboxamides with (diisopinocampheyl)borane. Angew Chem Int Ed Engl 52(49):12888-12891. doi:10.1002/anie.201307302

8. Dhillon RS (2007) Hydroboration and organic synthesis: 9-borabicyclo[3.3.1]nonane (9-BBN). doi:10.1007/978-3-540-49076-0

9. Hu NF, Zhao GQ, Zhang YY, Liu XQ, Li GY, Tang WJ (2015) Synthesis of chiral alpha-amino tertiary boronic esters by enantioselective hydroboration of alpha-arylenamides. J Am Chem Soc 137(21):6746-6749. doi:10.1021/jacs.5b03760

10. Obligacion JV, Neely JM, Yazdani AN, Pappas I, Chirik PJ (2015) Cobalt catalyzed Z-selective hydroboration of terminal alkynes and elucidation of the origin of selectivity. J Am Chem Soc 137(18):5855-5858. doi:10.1021/jacs.5b00936

11. Zhang L, Zuo ZQ, Wan XL, Huang Z (2014) Cobalt-catalyzed enantioselective hydroboration of 1,1-disubstituted aryl alkenes. J Am Chem Soc 136(44):15501-15504. doi:10.1021/ja5093908

12. Klotter F, Studer A (2015) Short and divergent total synthesis of $(+)$-machaeriol B, (+)-machaeriol D, (+)-delta(8)-THC, and analogues. Angew Chem Int Ed Engl 54(29):8547-8550. doi:10.1002/anie.201502595

13. Yang Y, Xu M, Song D (2015) Organocatalysts with carbon-centered activity for $\mathrm{CO}_{2}$ reduction with boranes. Chem Commun (Camb UK) 51(56):11293-11296. doi:10.1039/c5cc04337a

14. Niu H, Dong J-Y (2015) Regio-chemistry control in propylene/ isoprene copolymerization by metallocene catalysts. Polym Int 64(8):1023-1029. doi:10.1002/pi.4878

15. Brown HC, Negishi EI, Burke PL (1971) Organoboranes. 12. Hydroboration of 1,3-butadiene with borane in tetrahydrofuran in a ratio equal to or smaller than 11 -interconversion between B-alkylborolanes and 1,2-tetramethylenediboranes. J Am Chem Soc 93(14):3400. doi:10.1021/ja00743a017

16. Brown HC, Negishi EI, Gupta SK (1970) Reaction of B-methoxydialkylboranes with lithium aluminum hydride in presence of olefins-a new and general synthesis of acyclic and cyclic mixed trialkylboranes and their conversion into corresponding trialkylcarbinols via carbonylation-oxidation. J Am Chem Soc 92(22):6648. doi:10.1021/ja00725a050

17. Andreou A, Leskes M, Jambrina PG, Tustin GJ, Grey CP, Rosta E, Scherman OA (2015) Divergence from the classical hydroboration reactivity; boron containing materials through a hydroboration cascade of small cyclic dienes. Chem Sci. doi:10.1039/ C4SC02729A

18. Brown HC, Bhat KS (1986) Hydroboration 76. Hydroboration of cyclic dienes with representative hydroborating agents. J Org Chem 51(4):445-449. doi:10.1021/jo00354a005

19. Zweifel G, Nagase K, Brown HC (1962) Hydroboration. XIII. The hydroboration of dienes with disiamylborane. A convenient procedure for the conversion of selected dienes into unsaturated alcohols. J Am Chem Soc 84(2):190-195

20. Zweifel G, Nagase K, Brown HC (1962) Hydroboration. XII. The hydroboration of dienes with diborane. J Am Chem Soc 84(2):183-189. doi:10.1021/ja00861a012

21. Houk KN, Rondan NG, Wu Y-D, Metz JT, PaddonRow MN (1984) Theoretical studies of stereoselective hydroborations. Tetrahedron 40(12):2257-2274. doi:10.1016/0040-4020(84)80009-5

22. Ess DH, Kister J, Chen M, Roush WR (2009) Quantum-mechanical study of 10-R-9-borabicyclo[3.3.2]decane alkene hydroboration. J Org Chem 74(22):8626-8637. doi:10.1021/jo901737d

23. Ilich P-P, Rickertsen LS, Becker E (2006) Polar addition to $\mathrm{C}=\mathrm{C}$ group: why is anti-Markovnikov hydroboration-oxidation of alkenes not "anti-"? J Chem Educ 83(11):1681. doi:10.1021/ ed083p1681

24. Oyola Y, Singleton DA (2009) Dynamics and the failure of transition state theory in alkene hydroboration. J Am Chem Soc 131(9):3130-3131. doi:10.1021/ja807666d 
25. Zheng J, Papajak E, Truhlar DG (2009) Phase space prediction of product branching ratios: canonical competitive nonstatistical model. J Am Chem Soc 131(43):15754-15760. doi:10.1021/ ja904405v

26. Glowacki DR, Liang CH, Marsden SP, Harvey JN, Pilling MJ (2010) Alkene hydroboration: hot intermediates that react while they are cooling. J Am Chem Soc 132(39):13621-13623. doi:10.1021/ja105100f

27. Breneman CM, Wiberg KB (1990) Determining atom-centered monopoles from molecular electrostatic potentials. The need for high sampling density in formamide conformational analysis. J Comput Chem 11(3):361-373. doi:10.1002/jcc.540110311

28. Stephan DW (2015) Frustrated Lewis pairs: from concept to catalysis. Acc Chem Res 48(2):306-316. doi:10.1021/ar500375j

29. Uzarewicz A (1964) Rocz Chem 38:599

30. Uzarewicz A (1964) Rocz Chem 38:385

31. Matsumi N, Chujo Y (1997) Synthesis of novel organoboron polymers by hydroboration polymerization of bisallene compounds. Polym Bull (Berl) 38(5):531-536. doi:10.1007/s002890050083

32. Andreou A (2013) Synthesis and reactivity of boron hydrides for the preparation of chiral diboranes and bis-phosphines. University of Cambridge, Cambridge

33. Fukui K (1981) The path of chemical reactions-the IRC approach. Acc Chem Res 14(12):363-368. doi:10.1021/ ar00072a001

34. Brown HC, Negishi EI (1972) The cyclic hydroboration of dienes. A simple convenient route to heterocyclic organoboranes. Pure Appl Chem 29:527-545

35. Brown HC, Negishi E, Burke PL (1970) Facile opening of the borolane ring with borane. A simple entry into 1,2-tetramethylenediboranes. J Am Chem Soc 92(22):6649-6651. doi:10.1021/ ja00725a051
36. Frisch MJ, Trucks GW, Schlegel HB, Scuseria GE, Robb MA, Cheeseman JR, Scalmani G, Barone V, Mennucci B, Petersson GA, Nakatsuji H, Caricato M, Li X, Hratchian HP, Izmaylov AF, Bloino J, Zheng G, Sonnenberg JL, Hada M, Ehara M, Toyota K, Fukuda R, Hasegawa J, Ishida M, Nakajima T, Honda Y, Kitao O, Nakai H, Vreven T, Montgomery JA Jr, Peralta JE, Ogliaro F, Bearpark MJ, Heyd J, Brothers EN, Kudin KN, Staroverov VN, Kobayashi R, Normand J, Raghavachari K, Rendell AP, Burant JC, Iyengar SS, Tomasi J, Cossi M, Rega N, Millam NJ, Klene M, Knox JE, Cross JB, Bakken V, Adamo C, Jaramillo J, Gomperts R, Stratmann RE, Yazyev O, Austin AJ, Cammi R, Pomelli C, Ochterski JW, Martin RL, Morokuma K, Zakrzewski VG, Voth GA, Salvador P, Dannenberg JJ, Dapprich S, Daniels AD, Farkas Ö, Foresman JB, Ortiz JV, Cioslowski J, Fox DJ (2009) Gaussian 09. Gaussian Inc, Wallingford

37. Neese F (2012) The ORCA program system. Wiley Interdiscip Rev Comput Mol Sci 2(1):73-78. doi:10.1002/wcms.81

38. Ditchfield R, Hehre WJ, Pople JA (1971) Self-consistent molecular-orbital methods. IX. An extended Gaussian-type basis for molecular-orbital studies of organic molecules. J Chem Phys 54(2):724-728

39. Grimme S, Antony J, Ehrlich S, Krieg H (2010) A consistent and accurate $a b$ initio parameterization of density functional dispersion correction (DFT-D) for the 94 elements H-Pu. J Chem Phys 132:154104

40. Singh UC, Kollman PA (1984) An approach to computing electrostatic charges for molecules. J Comput Chem 5(2):129-145. doi: $10.1002 /$ jec. 540050204

41. Wolinski K, Hilton JF, Pulay P (1990) Efficient implementation of the gauge-independent atomic orbital method for NMR chemical shift calculations. J Am Chem Soc 112(23):8251-8260. doi:10.1021/ja00179a005 